\title{
Morphologic variant of follicular lymphoma reminiscent of hyaline-vascular Castleman disease
}

\author{
Jiwon Koh ${ }^{1}$, Yoon Kyung Jeon ${ }^{1,2}$ \\ 'Department of Pathology, Seoul National University Hospital, Seoul; 2Department of Pathology, Seoul National University College of Medicine, Seoul, Korea
}

\begin{abstract}
Follicular lymphoma (FL) with hyaline-vascular Castleman disease (FL-HVCD)-like features is a rare morphologic variant, with fewer than 20 cases in the literature. Herein, we report a case of FL-HVCD in a 37-year-old female who presented with isolated neck lymph node enlargement. The excised lymph node showed features reminiscent of HVCD, including regressed germinal centers (GCs) surrounded by onion skin-like mantle zones, lollipop lesions composed of hyalinized blood vessels penetrating into regressed GCs, and hyalinized interfollicular stroma. In addition, focal areas of abnormally conglomerated GCs composed of homogeneous, small centrocytes with strong BCL2, CD10, and BCL6 expression were observed, indicating partial involvement of the FL. Several other lymphoid follicles showed features of in situ follicular neoplasia. Based on the observations, a diagnosis of FL-HVCD was made. Although FLHVCD is very rare, the possibility of this variant should be considered in cases resembling CD. Identification of abnormal, neoplastic follicles and ancillary immunostaining are helpful for proper diagnosis.
\end{abstract}

Key Words: Malignant lymphoma; Follicular lymphoma; Hyaline-vascular Castleman disease; In situ follicular neoplasia

Received: November 13, 2019 Revised: December 9, 2019 Accepted: December 17, 2019

Corresponding Author: Yoon Kyung Jeon, MD, PhD, Department of Pathology, Seoul National University Hospital, Seoul National University College of Medicine, 101 Daehak-ro, Jongno-gu, Seoul 03080, Korea

Tel: +82-2-740-8323, Fax: +82-2-743-5530, E-mail: ykjeon@snu.ac.kr

Follicular lymphoma (FL) is an indolent B-cell lymphoma and the second most common non-Hodgkin lymphoma (NHL) in the western world [1]. FL is the third most common form of B-cell NHL in Korea, accounting for $7.1 \%$ of all malignant lymphomas [2]. Several morphological variants of FL exist, including marginal zone variant, floral variant, and sclerosing variant [3-5]. Although typical cases of FL lead to straightforward diagnosis, the morphological variants are sometimes very challenging, rendering proper diagnosis difficult for pathologists. Herein, we describe a case of $\mathrm{FL}$ with hyaline-vascular Castleman disease (FL-HVCD)-like features, an extremely rare morphological variant.

\section{CASE REPORT}

A 37-year-old female presented with a palpable right neck mass that had been found one month prior. She denied having any previous medical problems, except anemia. On review of systems, she denied fever, unintentional weight loss, or night sweats. Enlargement of the right cervical lymph node (LN) was found on physical examination, and complete blood count revealed decreased hemoglobin level $(10.5 \mathrm{~g} / \mathrm{dL})$; white blood cell and platelet counts were within normal limits. Neck ultrasonography showed a 3.5-cm-sized mass in the right neck (Fig. 1A), and computed tomography scan confirmed a well-enhanced LN along with smaller LNs in the right cervical level II area (Fig. 1B). On ${ }^{18} \mathrm{~F}$-positron emission tomography scan, an enlarged LN in the right level II area was found with maximal standardized uptake value of 4.0; no other hypermetabolic lesions were found, except for the mild physiologic uptake at bilateral tonsils and oropharynx (Fig. 1C). Overall, the clinical impression was consistent with benign lymphoproliferative disease or localized lymphoma.

The patient underwent needle biopsy of the right cervical LN. Microscopic examination revealed a small fragment of LN tissue showing relatively preserved nodular LN structure. BCL2 was diffusely positive with more intense staining within the germinal center (GC); GC areas were also positive for $\mathrm{CD} 20$, 

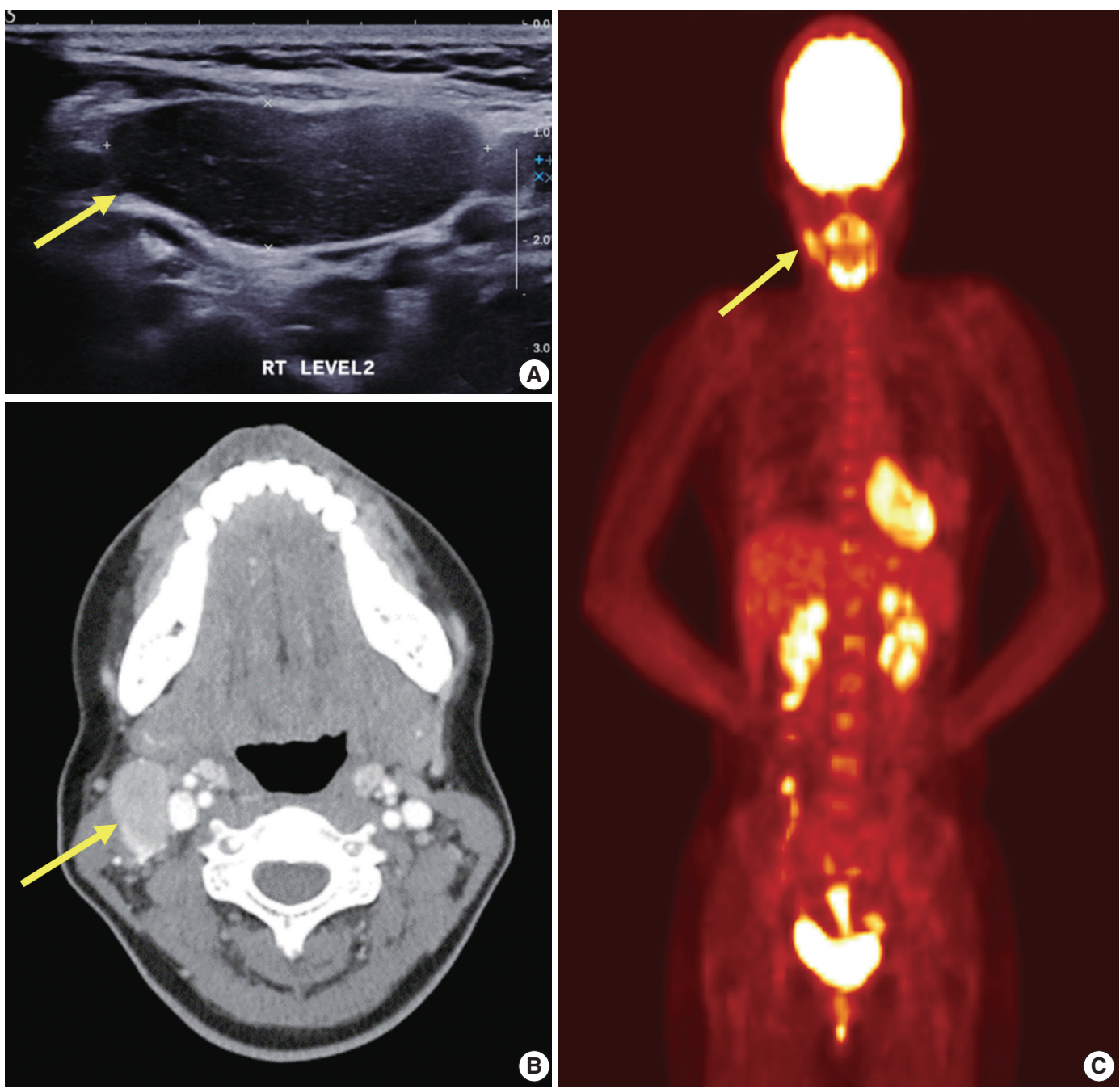

Fig. 1. Imaging work-up of the patient at presentation. (A) Neck ultrasonography shows a hypoechoic mass (arrow). (B) Neck computed tomography shows a well-enhanced ovoid mass at level II area (arrow). (C) ${ }^{18} \mathrm{~F}$-positron emission tomography scan shows hypermetabolic lesion in the right neck (arrow) and no other hypermetabolic lesions.

BCL6, and CD10 with low Ki-67 proliferation index. Possibilities of both in situ follicular neoplasia (ISFN) and partially biopsied FL was considered, and complete excision of the LN was recommended.

On microscopic examination, the excised neck LN was composed of numerous regressed GCs surrounded by expanded mantle zones (Fig. 2A, B), often showing concentric distribution of small lymphocytes (onion skin pattern) (Fig. 2C) and follicles separated by hyalinized interfollicular stroma. In addition, hyalinized blood vessels penetrating into regressed GCs, forming a typical "lollipop" appearance, were observed (Fig. 2D). Although predominant histological features of the excised LN were suggestive of HVCD, several conglomerated follicles with GCs composed of small, monotonous, and centrocyte-like lymphocytes were found on careful examination (Fig. 3A, B).
As shown in Fig. 3B, BCL2-positive, BCL6-positive, and CD10-positive B-cells were identified within the abnormally conglomerated GCs. The presence of neoplastic follicles showing structural abnormality and aberrant immunophenotype indicated FL (in the form of partial nodal involvement). In addition, some follicles with relatively preserved structure and polarity also harbored BCL2-positive, BCL6-positive, and CD10-positive B-cells (Fig. 3C), which is consistent with ISFN. Neoplastic cells were also present within typical HVCD-looking regressed follicles, as shown in Fig. 2E. Final pathologic diagnosis of FL grade 1 was made, with additional remarks stating that HVCDlike features were noted. Subsequent bone marrow examination confirmed no evidence of lymphoma involvement; therefore, the patient was finally diagnosed with FL grade 1, Ann Arbor stage I, and no further treatment was initiated. 


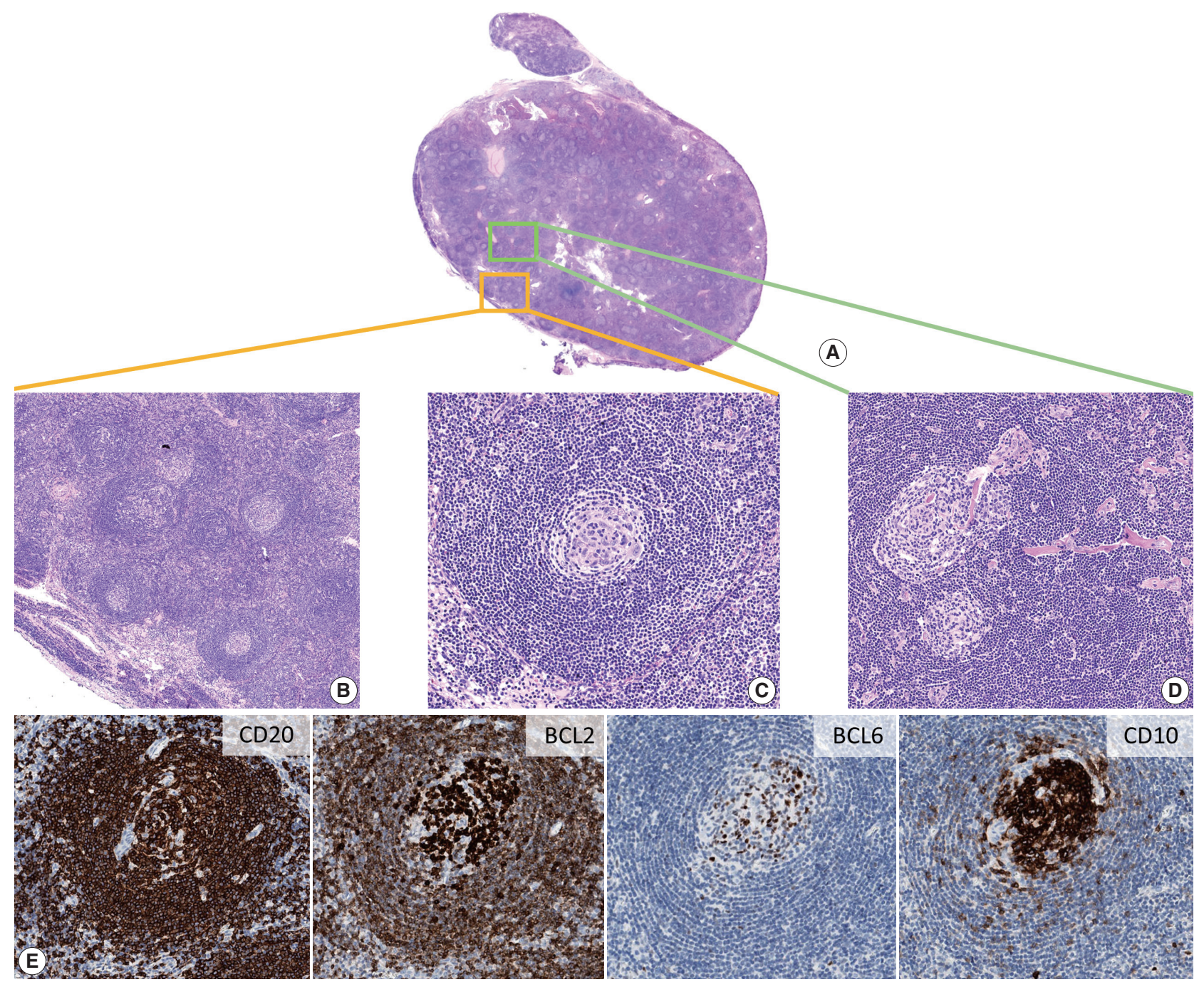

Fig. 2. Excised lymph node reminiscent of hyaline-vascular Castleman disease (HVCD). Vaguely nodular pattern is noted on low power (A), where regressed lymphoid follicles (B) with expanded onion skin-like mantle zones (C) are observed. (D) Hyalinized blood vessels within follicles are frequently noted. (E) Immunostaining shows the presence of BCL2-positive, BCL6-positive, and CD10-positive cells within the regressed follicles.

\section{Ethics statement}

The Institutional Review Board of Seoul National University Hospital (SNUH) approved this study (No. H-1911-032-107) and waived the need for written informed consent from the patient.

\section{DISCUSSION}

The incidence of FL in Korea is increasing over time; compared with the 2005-2006 statistics [6], the proportion of FL has increased 2.5-fold from 2015-2016, becoming the third most common form of B-cell NHL in Korea, following diffuse large B-cell lymphoma and extranodal marginal zone B-cell lymphoma of mucosa-associated lymphoid tissue [2]. Due to the overall increase in incidence, pathologists are more likely to encounter FL variants in daily practice; therefore, awareness of rare morphological variants is important for accurate identification and diagnosis.

FL-HVCD was first described in 1994 [7], and only 11 cases have been reported in the English literature to date [8-12]. Pina-Oviedo et al. [12] reviewed and reported clinicopathological findings of these cases. All previously reported patients were older than the patient in the present study, and median age at diagnosis was 63 years (range, 41 to 77 years). The patients presented with a wide range of symptoms from asymptomatic, incidentally found lesion to generalized lymphadenopathy. Eight 


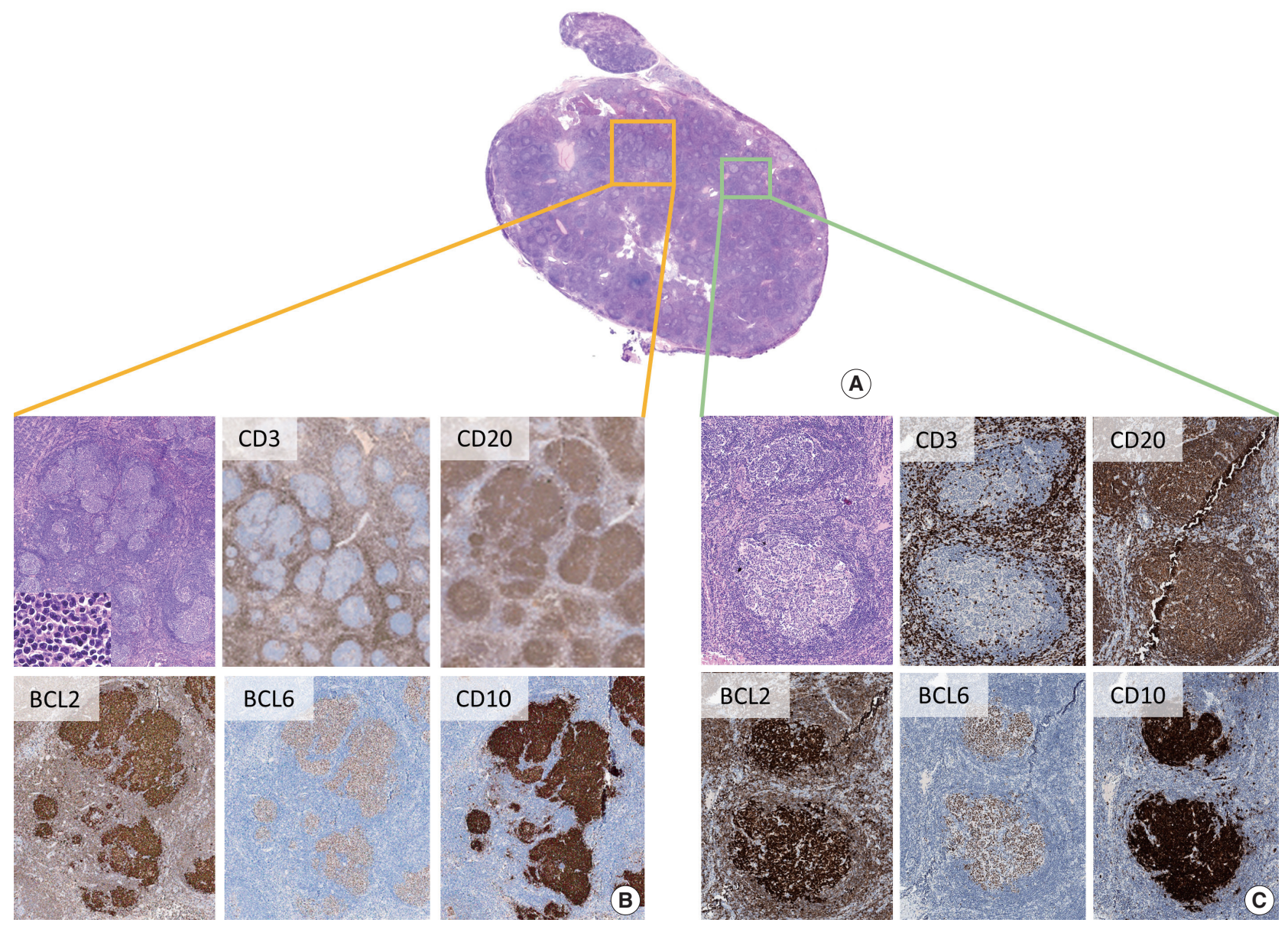

Fig. 3. Features of follicular lymphoma. Upon careful examination, abnormally conglomerated follicles are identified (A, B), and presence of BCL2-positive, BCL6-positive, and CD10-positive neoplastic B-cells is noted (B), confirming follicular lymphoma. (C) In addition, cells having an aberrant BCL2-positive, BCL6-positive, and CD10-positive immunophenotype within otherwise normal-looking follicles are observed, indicating involvement of in situ follicular neoplasia (ISFN).

of 11 patients received either chemotherapy or radiation therapy, and recurrence or death from the disease has not been reported to date. Morphologically, cases were reported to have several HVCD features including hyalinized blood vessels penetrating regressed GCs, increased vascularity in interfollicular stroma, and onion skin-like mantle zones, complicating differential diagnosis. However, all cases harbored at least one focal area showing conventional FL histology.

The current case differs from previously reported FL-HVCD cases in several aspects. First, the patient had localized disease, presenting with an incidentally found, isolated neck mass with no evidence of systemic lymphadenopathy. In addition, the patient was 37 years old, which is relatively young for FL to be included in the differential diagnosis, considering the median age of FL patients at presentation is approximately 60 years. These two factors complicated the diagnostic process: considering both clinical features and histopathologic characteristics of the patient, unicentric HVCD was the most likely diagnosis. However, identification of abnormally conglomerated follicles that contained densely packed centrocytes was critical for suspicion of a neoplastic process. The immunostaining of $\mathrm{CD} 20$, BCL2, BCL6, and CD10 showed conglomerated follicles replaced with BCL2-positive neoplastic GC-type B-cells, resulting in diagnosis of FL-HVCD.

Due to the rare incidence, FL-HVCD is one of the most underrecognized variants of FL. Furthermore, the underlying etiologic mechanism of this disease is obscure. Hypothetically, FL-HVCD is a coincidence in which FL involves an LN that previously underwent CD-like changes [12]. Furthermore, because FL cells are dependent on follicular dendritic cells for survival $[13,14]$ and are important for the pathogenesis of HVCD [15], there might be a pathogenic link between FL and HVCD. To further clarify this condition, long-term follow-up of FL-HVCD patients may provide additional information. 
Distinction of FL-HVCD from CD is critically important, mostly due to therapeutic perspective. Though alleged to be indolent, FLs are a lymphoid malignancy, warranting systemic staging work-up upon diagnosis. Patients with symptomatic or advanced stage should be advised to receive therapeutic intervention [16]. Therefore, possibility of FL-HVCD should be considered a differential diagnosis when a specimen shows typical HVCD features.

In summary, we report a case of FL-HVCD. Acknowledgment of rare FL variants and thorough microscopic examination to identify at least a focal area suggestive of neoplastic follicles are helpful for accurate diagnosis of FL-HVCD.

\section{ORCID}

Jiwon Koh: https://orcid.org/0000-0002-7687-6477

Yoon Kyung Jeon: https://orcid.org/0000-0001-8466-9681

\section{Author Contributions}

Conceptualization: YKJ.

Data curation: JK, YKJ.

Formal analysis: JK, YKJ.

Investigation: JK, YKJ.

Visualization: JK.

Writing—original draft: JK, YKJ.

Writing—review \& editing: JK, YKJ.

\section{Conflicts of Interest}

The authors declare that they have no potential conflicts of interest.

\section{Funding}

No funding to declare.

\section{REFERENCES}

1. Harris NL, Swerdlow SH, Jaffe ES, et al. Follicular lymphoma. In: Swerdlow SH, Campo E, Harris NL, et al., eds. WHO classification of tumours of haematopoietic and lymphoid tissues. 4th ed. Lyon: IARC Press, 2008; 220-6.

2. Jung HR, Huh J, Ko YH, et al. Classification of malignant lymphoma subtypes in Korean patients: a report of the 4th nationwide study. J Hematopathol 2019; 12: 173-81.

3. Goodlad JR, Batstone PJ, Hamilton D, Hollowood K. Follicular lymphoma with marginal zone differentiation: cytogenetic findings in support of a high-risk variant of follicular lymphoma. Histopathology 2003; 42: 292-8.
4. Goates JJ, Kamel OW, LeBrun DP, Benharroch D, Dorfman RF. Floral variant of follicular lymphoma. Immunological and molecular studies support a neoplastic process. Am J Surg Pathol 1994; 18: 37-47.

5. Kojima M, Matsumoto M, Miyazawa Y, Shimizu K, Itoh H, Masawa N. Follicular lymphoma with prominent sclerosis ("sclerosing variant of follicular lymphoma") exhibiting a mesenteric bulky mass resembling inflammatory pseudotumor: report of three cases. Pathol Oncol Res 2007; 13: 74-7.

6. Kim JM, Ko YH, Lee SS, et al. WHO classification of malignant lymphomas in Korea: report of the third nationwide study. Korean J Pathol 2011; 45: 254-60.

7. Warnke RA, Weiss LM, Chan JK, Cleary ML, Dorfman RF. Tumors of the lymph nodes and spleen. In: Rosai J, Sobin LH, eds. Atlans of tumor pathology. 3rd series. Washington, DC: Armed Forces Institute of Pathology, 1994; 85.

8. Nozawa Y, Hirao M, Kamimura K, Hara Y, Abe M. Unusual case of follicular lymphoma with hyaline-vascular follicles. Pathol Int 2002; 52: 794-5.

9. Kojima M, Sakurai S, Isoda A, Tsukamoto N, Masawa N, Nakamura N. Follicular lymphoma resembling with hyaline-vascular type of Castleman's disease: the morphological and immunohistochemical findings of two cases. Cancer Ther 2009; 7: 109-12.

10. Siddiqi IN, Brynes RK, Wang E. B-cell lymphoma with hyaline vascular Castleman disease-like features: a clinicopathologic study. Am J Clin Pathol 2011; 135: 901-14.

11. Pina-Oviedo S, Wang W, Vicknair E, Manning JT Jr, Medeiros LJ. Follicular lymphoma with hyaline-vascular Castleman disease-like follicles and CD20 positive follicular dendritic cells. Pathology 2017; 49: 544-7.

12. Pina-Oviedo S, Miranda RN, Lin P, Manning JT, Medeiros LJ. Follicular lymphoma with hyaline-vascular Castleman-like features: analysis of 6 cases and review of the literature. Hum Pathol 2017; 68: $136-46$

13. Kagami Y, Jung J, Choi YS, et al. Establishment of a follicular lymphoma cell line (FLK-1) dependent on follicular dendritic cell-like cell line HK. Leukemia 2001; 15: 148-56.

14. Takata K, Sato Y, Nakamura N, et al. Duodenal and nodal follicular lymphomas are distinct: the former lacks activation-induced cytidine deaminase and follicular dendritic cells despite ongoing somatic hypermutations. Mod Pathol 2009; 22: 940-9.

15. Chang KC, Wang YC, Hung LY, et al. Monoclonality and cytogenetic abnormalities in hyaline vascular Castleman disease. Mod Pathol 2014; 27: 823-31.

16. Freedman A. Follicular lymphoma: 2015 update on diagnosis and management. Am J Hematol 2015; 90: 1171-8. 